Classification

Physics Abstracts

$07.80-68.48-81.30 \mathrm{M}$

\title{
Fine scale investigation of some phenomena in metallic alloys by field ion microscopy and atom probe microanalysis
}

\author{
Didier Blavette and Pierre Auger
}

Laboratoire de microscopie ionique URA CNRS 808, UFR Science, BP 118, 76134 Mt St Aignan Cedex, France

(Received October 01, 1990; accepted January 15, 1991)

\begin{abstract}
Résumé. - La sonde atomique à émission de champ est une technique de microanalyse quantitative à haute résolution spatiale. La résolution en surface est de l'ordre de $1 \mathrm{~nm}$ alors que celle en profondeur peut atteindre un plan réticulaire. Dans cet article, les possibilités de la sonde atomique en sciences des matériaux sont illustrées à partir de différentes recherches que nous menons actuellement au laboratoire. Il s'agit par exemple de l'étude de la structure fine ou de la ségrégation intergranulaire dans des superalliages à base nickel. Les investigations que nous menons sur les processus de décomposition spinodale dans la phase ferritique d'aciers duplex sont également évoquées. Enfin, l'étude des modulations d'ordre à grande distance associées aux parois d'antiphase dans les phases incommensurables $\mathrm{Cu}_{3} \mathrm{Pd}$ à longue période est discutée.
\end{abstract}

\begin{abstract}
The atom-probe is a microanalysis technique with high spatial resolution. The lateral resolution is close to $1 \mathrm{~nm}$ while the depth resolution may reach a single atomic layer. In this article, the atom-probe potentialities in material science are illustrated with the help of various experiments we conduct at present. The study of the fine scale microstructure of nickel base superalloys including that of grain boundary segregation is reported. The investigations we perform on the spinodal decomposition of the ferritic phase of a duplex stainless steel are also discussed. Lastly, the study of long range order modulations related to APB's which occur in incommensurate long period phases $\mathrm{Cu}_{3} \mathrm{Pd}$ is commented.
\end{abstract}

The field-ion microscope was invented by Muller in 1951 [1]. With this instrument, an atomic resolution image could be achieved for the first time. However, it was not before the early $1960 \mathrm{~s}$ that field-ion microscopy was applied to material sciences. With the introduction of atom-probe techniques by Muller in 1968 [2], it was possible to identify unambiguously the chemical nature of

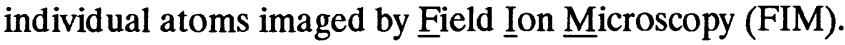

The Atom-Probe (AP) combines the possibilities of the FIM with that of a single particle sensitive time of flight mass spectrometer. A small selected area of the material may be quantitatively analysed with a very high spatial resolution. By field evaporation, the surface atoms of the specimen can be removed and analysed. As a result, a concentration profile may be constructed, layer after layer, with a spatial resolution of one atomic plane in depth. Atom-probe investigation of a material may be interpreted as the analysis of the specimen along a cylinder (Fig. 1). The lateral 
resolution is not physically limited in principle and could be equivalent to one or two atomic distances. However, the concept of concentration profile requires the use of a reasonable number of collected ions per layer. In order to maintain the statistical fluctuations to an acceptable level as well as to preserve the lateral resolution, the diameter of the analysed area is usually chosen close to $2 \mathrm{~nm}$. In addition, when the microanalysis takes place in the vicinity of an interface or a grain boundary, the occurence of geometrical aberrations in the ion trajectories leads to an additional degradation of the inherent lateral resolution of the analysis $(\sim 1 \mathrm{~nm})$.



Fig. 1. - Atom-Probe microanalysis of a material containing finely dispersed particles. The diameter of the analysis cylinder $\left(\Phi_{\mathbf{a}}\right)$ gives the lateral resolution.

In this contribution, we shall try to illustrate the possibilities of the FIM-Atom-Probe with the help of recent investigations we have undertaken. Because of the basic principle of these techniques, mainly Field Emission, early applications as well as most of the researches conducted to day deal with metallic materials. Despite some recent technological innovations (pulsed laser atom probe [3]) make the study of semi-conducting materials now feasible [4], we will restrict our contribution to metallic alloys.

Because of its high spatial resolution, the atom-probe is an attractive tool for the investigation of decomposition processes in metallic alloys. For instance, the early stages of precipitation in a model superalloy were studied few years ago. It was possible to show how the phase composition as well as the particle diameter and the number density of precipitates evolve during the kinetics of transformation [5]. Some recent researches dealing with spinodal decomposition of the chromium rich ferritic phase of a duplex stainless steel will be reported here. We shall show how the amplitude as well as the wavelength of the concentration fluctuations which occur on a very fine scale in the material $(\lambda \sim 4 \mathrm{~nm})$ may be derived from atom-probe data.

The atom-probe is also a powerful technique for the chemical microanalysis and the observations of interfaces or grain boundaries as well as for the detection of subtle effects which may occur in a solid solution (clustering, fine-scale concentration modulations...). We shall illustrate these possibilities frum experiments we pertormed on some nickel base superalloys.

When the analysis is located on a superstructure layer, it is possible to investigate the long range order fluctuations which may occur in an ordered phase. We shall report the results we obtained on the incommensurate phases observed in long period $\mathrm{Cu}_{3} \mathrm{Pd}$ alloys. 


\section{Experimental.}

The principle of atom-probe techniques is essentially based on two processes: FIM images are obtained by field ionisation of a rare gas near the surface of the material and atom-probe microanalysis of the sample is achieved by field evaporation of surface atoms. Both physical phenomena need a very high field $(30-50 \mathrm{~V} / \mathrm{nm})$ which is reached by applying a positive voltage $(\simeq 10 \mathrm{kV})$ to the specimen elaborated in the form of a sharply pointed needle $(R \simeq 50 \mathrm{~nm})$. The specimen is mounted onto a goniometer head and can be rotated in such a way that the specific region of interest (precipitate, grain boundary) may be mass analysed. The surface atoms of the specimen are field evaporated by high-voltage pulses $\left(V_{\mathrm{p}}\right)$ which are superimposed on the standing voltage $V_{\mathrm{o}}$ (used for FIM images). The mass of chemical species originating from the small selected area is measured by time of flight mass spectrometry.

A typical FIM image of a two-phase material is provided in figure 2. This micrograph shows the presence of small $\gamma^{\prime}$ precipitates in a nickel base superalloy [6]. $\gamma^{\prime}$ particles of a few hundred Angströms appear in bright contrast while the surrounding matrix remains dark. Atomic resolution is not reached in this complex alloy. The related mass spectrum of the $\gamma^{\prime}$ phase is given in figure 3 as an example.

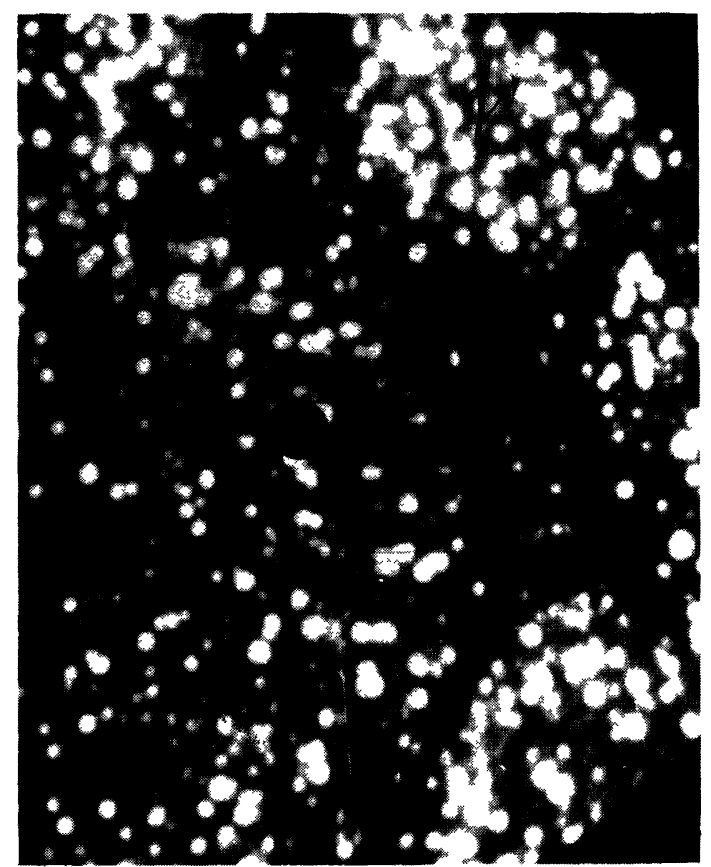

Fig. 2. - Field ion micrograph of a nickel based superalloy containing small ordered $\gamma^{\prime}$ particules $\left(\mathrm{Ni}_{3}(\mathrm{Al}\right.$, $\mathrm{Ti})$ ), a few ten nanometers in diameter. The probe hole is located on a brightly imaged precipitate. Only ions, field evaporated from the central region of the aiming ring (dark circle), are mass analysed with the atom-probe.

The basic features of precipitates clearly appear in this figure: $\gamma^{\prime}$ is an aluminium and titanium rich phase. In contrast, as shown in table I, the darkly imaged $\gamma$ solid solution contains a high 


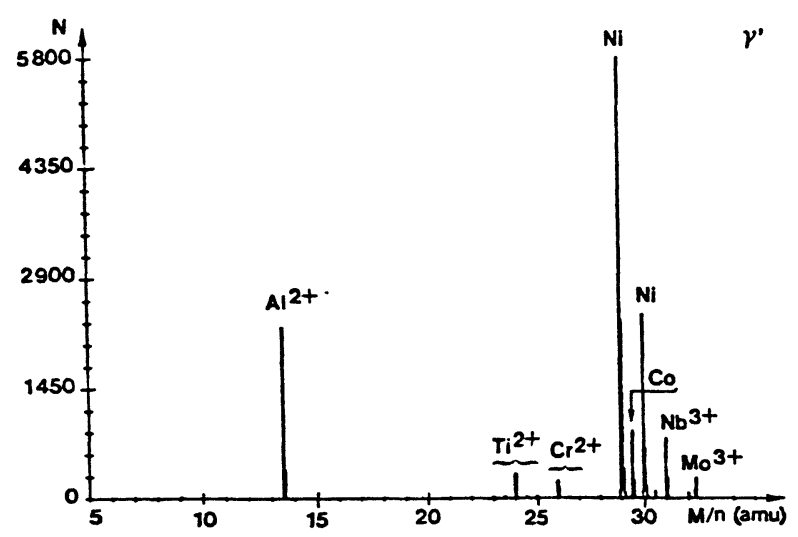

Fig. 3. - High resolution mass spectrum related to $\gamma^{\prime}$ precipitates imaged in figure 2. Atoms are field evaporated as doubly $(\mathrm{Al}, \mathrm{Ti}, \mathrm{Ni}, \mathrm{Co}, \mathrm{Cr})$ and triply charged ions (Mo, $\mathrm{Nb})$.

level of chromium, cobalt and molybdenum. These results have been obtained with an energy compensated spectrometer the design of which is very close to that described by Andren $e t$ al. [7]. With such a spectrometer, a mean resolution greater than $M / \Delta M=1000$ (full width half maximum) is routinely achieved; cobalt as well as molybdenum peaks are here clearly resolved.

Table I. - Phase composition of the nickel base superalloy

\begin{tabular}{|c|c|c|c|c|c|c|c|}
\hline at.\% & $\mathrm{Al}$ & $\mathrm{Ti}$ & $\mathrm{Cr}$ & $\mathrm{Ni}$ & $\mathrm{Co}$ & $\mathrm{Nb}$ & $\mathrm{Mo}$ \\
\hline$\gamma$ & 1.94 & 0.38 & 24.97 & 51.80 & 14.97 & 0.90 & 5.60 \\
\hline$\gamma^{\prime}$ & 13.85 & 4.33 & 2.14 & 66.40 & 6.00 & 5.56 & 1.38 \\
\hline
\end{tabular}

It is noteworthy to recall that AP techniques do not need the use of ionisation ratios. When the experimental conditions are properly settled (a very good vacuum $\left(<10^{-9}\right.$ Torr) is required, the pulse fraction $\left(V_{\mathrm{p}} / V_{\mathrm{o}}\right)$ must be high enough (15-20\%), the tip is held at low temperatures (40$80 \mathrm{~K})$, low detection rates ( $0.02 \mathrm{ion} / \mathrm{pulse})$ have to be maintained), all field evaporated atoms are ionised and detected with the same efficiency [8]. The compositions are simply deduced from the numbers of collected ions of each nature ( $\mathrm{Al}, \mathrm{Ni}, \mathrm{Cr} . .$.$) . Table II gives for comparison the$ bulk composition of the superalloy and the mean composition as deduced from atom-probe data. These latter concentrations have been computed from the level rule with a volume fraction equal to $60 \%$. Both composition data are very close to each other. This demonstrates that atom-probe data are consistent with the bulk composition of the material.

Field Ion Microscopy (FIM) as well as atom-probe microanalyses are conducted with the specimen at cryogenic temperatures. As a result, no surface migration or diffusion occurs. Further informations on FIM as well as on the application of AP techniques in material sciences may be found elsewhere $[9,10]$. 
Table II. - Nominal composition of the superalloy as compared to the overall composition as deduced from atom - probe data.

\begin{tabular}{|l|c|c|c|c|c|c|c|}
\hline \multicolumn{1}{|c|}{ at\% } & $\mathrm{Al}$ & $\mathrm{Ti}$ & $\mathrm{Cr}$ & $\mathrm{Ni}$ & $\mathrm{Co}$ & $\mathrm{Nb}$ & $\mathrm{Mo}$ \\
\hline $\begin{array}{l}\text { Nominal } \\
\text { Composition }\end{array}$ & 8.66 & 2.55 & 10.96 & 60.79 & 10.13 & 3.74 & 2.99 \\
\hline $\begin{array}{l}\text { Overall composition } \\
\text { as deduced from } \\
\text { atom - probe data }\end{array}$ & 9.09 & 2.75 & 11.27 & 60.56 & 9.60 & 3.70 & 3.07 \\
\hline
\end{tabular}

\section{Microanalyses of interfaces and grain boundaries.}

We shall illustrate the atom-probe capabilities in the investigation of phase or grain boundaries on the basis of some investigations we recently performed on nickel-base superalloys.

These materials derive their excellent creep performances from the presence of $\gamma^{\prime}$ ordered precipitates ( $\mathrm{L}_{2}$ structure) finely dispersed in a FCC $\gamma$ solid solution (see Fig. 2). The composition of $\gamma^{\prime}$ particles is based on the stoichiometry $\mathrm{Ni}_{3} \mathrm{Al}$ (see Tab. I). As FIM images can show [11], $\gamma^{\prime}$ precipitates are fully coherent with the surrounding matrix. Starting from this latest information, it is interesting to get a finer description of $\gamma-\gamma^{\prime}$ interfaces on an atomic scale. For this purpose, we performed a layer-by-layer analysis of (001) planes in a direction which is thought to be perpendicular to the phase boundary of a $\gamma^{\prime}$ particle. The composition profile provided in figure 4 exhibits the fine-scale features of the interface. The curves clearly show the transition from the $\mathrm{Cr}$-rich $\gamma$ matrix to the Al-rich ordered precipitate. As atom-probe microanalysis is conducted on (001) layers, one observe the basic stacking sequence of (001) superstructure planes of the $\left(\mathrm{Ni}_{3} \mathrm{Al}\right) \gamma^{\prime}$ phase: Al-rich planes alternate with (Ni-rich) Al-depleted layers. This clearly gives the proof that a spatial resolution of a single atomic layer is obtained with atom-probe techniques. These composition profiles demonstrate that the phase transition occurs over one atomic layer. More, the interface is localized on an Al-rich mixed plane of the ordered precipitate. This mean that the phase boundary is ordered [11]. The presence of a Ni-rich plane (an Al-depleted layer) at the interface would lead to a disordered boundary. It is interesting to notice that this type of investigation allows the preferential sites of addition elements in the $\gamma^{\prime}$ ordered phase to be determined. Occupation frequencies may be deduced from the mean composition of both types of planes (mixed and pure layers) [12].

The atom-probe also provides unique advantages, as compared for instance to Auger spectroscopy, for the study of the microchemistry of grain boundaries. In situ composition profiles accross boundaries may be obtained. However, due to the large size of grains ( $\Phi \geq 20 \mu \mathrm{m})$ as compared to the volume which can be analysed with the atom-probe (the tip radius is equal to a few ten nanometers and the probed depth is typically no larger than $500 \mathrm{~nm}$ ), tips must be first examined by transmission electron microscopy. By using back polishing techniques [13], a grain boundary can be placed close to the tip apex and subsequently be analysed by atom-probe techniques [14].

A FIM image of a specimen first prepared by this procedure is given as an example in figure 5. In this nickel base superalloy, minor elements. (C, B, $\mathrm{Zr}$ ) are added in such a way to improve their ductility or their mechanical strength. In order to clarify the physical mechanisms responsible for this improvement, experiments were recently undertaken [15]. The micrograph shown in figure 


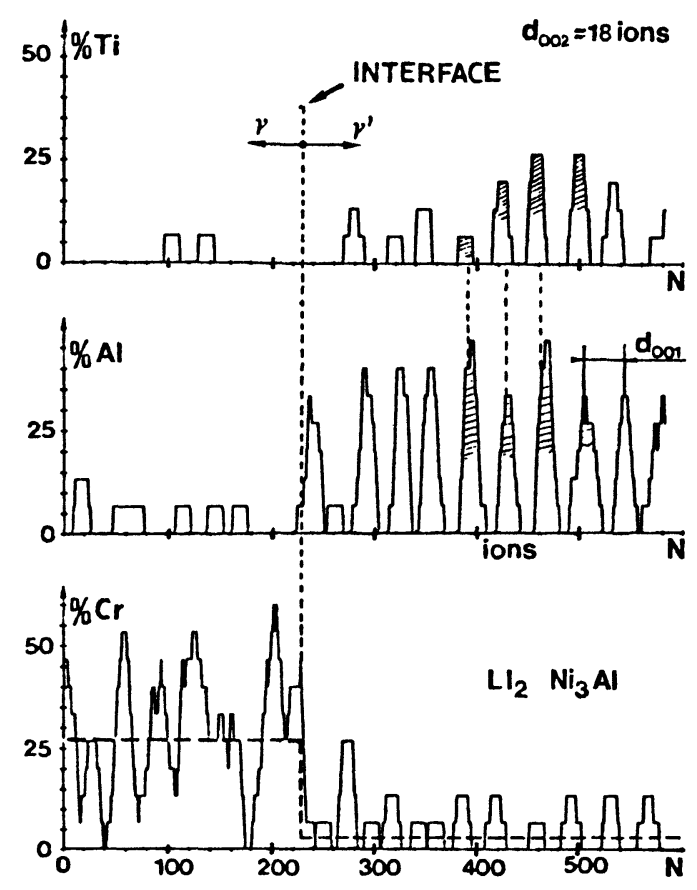

Fig. 4. - This composition profile exhibits the fine-scale features of the $\gamma-\gamma^{\prime}$ interface in a nickel-base superalloy. The $\gamma-\gamma^{\prime}$ transition accross the boundary takes place over a single (001) layer. The $\gamma-\gamma^{\prime}$ interface is located on an $\mathrm{Al}$-rich mixed plane of the ordered $\gamma^{\prime}$ phase. Note that Ti is observed to substitute preferentially for $\mathrm{Al}$ in the ordered $\mathrm{Ni}_{3} \mathrm{Al}$ phase.

5 clearly exhibits the presence of a decorated grain boundary. Despite this image suggests the occurence of a segregation, only atom-probe analyses can univocally give the nature of segregating elements.

The atom-probe investigations we conducted showed that brightly imaged spots were related to boron atoms. As shown in figure 6, boron segregates at grain boundaries ( 7 at $\%$ as compared to 0.11 at\% (bulk boron level)). The aluminium concentration profile clearly demonstrates that this segregation is located in a single phase boundary. The low level of aluminium shows that the boundary is located between two $\gamma$ regions. Intergranular $\gamma / \gamma^{\prime}$ interfaces were also found boron enriched. However, no boron segregation was detected to intragranular $\gamma / \gamma^{\prime}$ interfaces: large interstitial boron atoms are more likely to segregate to $\gamma / \gamma^{\prime}$ intergranular boundaries than to coherent $\gamma / \gamma^{\prime}$ transgranular interfaces. Such segragation effects have been already reported in $\mathrm{Ni}_{3} \mathrm{Al}$ intermetallic compounds $[16,17]$.

The concentration profiles given in figure 6 clearly exhibit the occurence of a nickel and aluminium depletion located at the boron enriched boundary. As shown in figures 5 and 6, the decorated grain boundary is relatively thick $(4 \mathrm{~nm})$. The average thickness of boron-rich regions is close to that observed by Stiller [18] in a boron doped nickel alloy. Carbon enrichments were also discovered in intergranular $\gamma / \gamma^{\prime}$ interfaces. A similar carbon segregation has been already reported in nickel by Alvensleben [19]. 


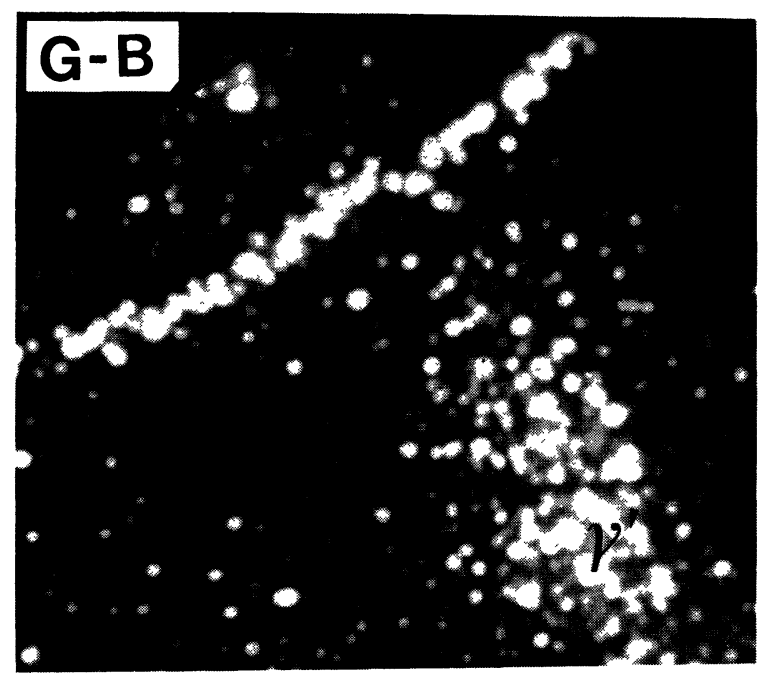

Fig. 5. - FIM image of a superalloy exhibiting a decorated grain boundary. A fine brightly imaged $\gamma^{\prime}$ precipitate is observed in the vicinity of the $\gamma-\gamma$ grain boundary.

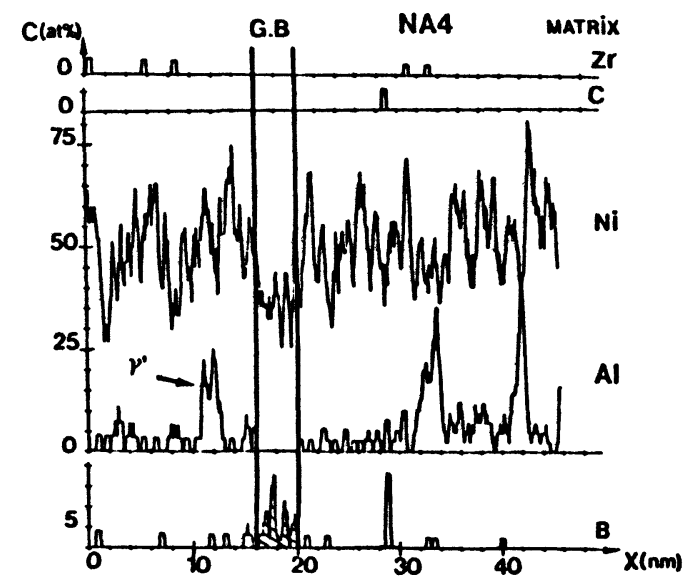

Fig. 6. - Composition profile related to the analysis of a $\gamma-\gamma$ grain boundary in a nickel-base superalloy. A local enrichment of boron at the boundary is exhibited and a well visible aluminium depletion is observed. Fine $\gamma^{\prime}$ precipitates are also present in the vicinity of the boundary.

3. Investigation of the spinodal decomposition process in the ferrite phase of a duplex stainless steel.

Low temperature heat-treatments produce an age-hardening embrittlement in the iron-chromium binary system and related stainless steels. The iron-chromium system contains a miscibility gap and exhibits spinodal decomposition which is somehow related to this embrittlement. The purpose of the present work was to study the decomposition kinetics of the ferrite phase of a duplex stainless steel aged at low temperatures $\left(300-400^{\circ} \mathrm{C}\right)$. This work was conducted in collaboration 
with EDF-département matériaux. Although the steel we studied is far from a model alloy (Cr: 26,3; Ni: 6.0; Si: 2,4; Mo: 2,1; Mn: 0,5; C; P; N; at\% for the ferrite phase) it is reasonable to think that a spinodal decomposition will also occur in this material after low temperature agingtreatments.

Because of its high spatial resolution and its capability to identify unambigously $\mathrm{Fe}, \mathrm{Cr}$ and $\mathrm{Ni}$, the AP allows the investigation of such a problem. FIM images of this steel aged at $400^{\circ} \mathrm{C}$ for a long time exhibit a duplex contrast which can be attributed to a fine-scale fully interconnected $\alpha / \alpha^{\prime}$ isotropic sponge-like microstructure [20]. Theses features have already been observed in $\mathrm{Fe}-\mathrm{Cr}, \mathrm{Fe}-\mathrm{Cr}-\mathrm{Co}, \mathrm{Fe}-\mathrm{Cr}-\mathrm{Ni}$ systems [21,22] and related steels [22,24].

Two main kinds of parameter are necessary for the characterization of the spinodal decomposition: the correlation distances related to the fluctuations of chromium concentration (or iron as well) and the amplitude of these fluctuations. From a topological point of view, this requires the estimation of the distances between chromium rich veins of the interconnected structure and the measurement of the chromium concentration in both $\alpha$ and $\alpha^{\prime}$ "phases".

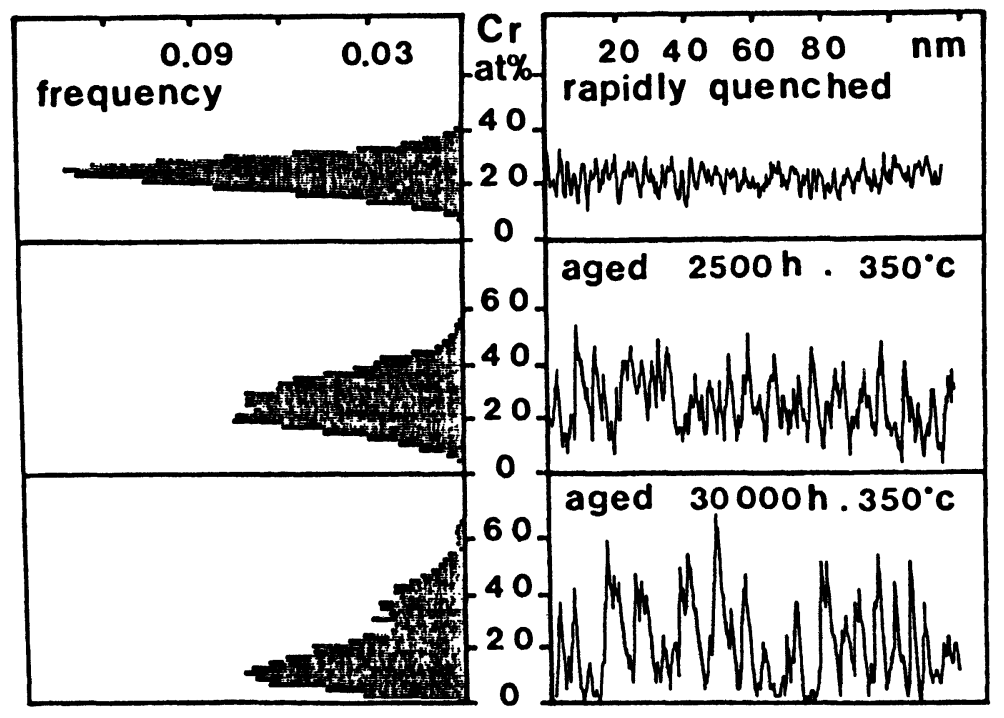

Fig. 7. - Series of chromium composition profiles as a function of aging time in the ferritic phase of a duplex stainless steel aged at $T=350^{\circ} \mathrm{C}$. The related concentration amplitude histograms show the evolution of fluctuations. The amplitude and the average wavelength of the composition modulations increase with time: the ferritic phase decomposes in a fine-scale mixture of $\alpha$ (chromium poor) and $\alpha^{\prime}$ (chromium rich) interconnected domains.

Figure 7 shows the chromium concentration profiles for different aging times at $350^{\circ} \mathrm{C}$ and the related concentration frequency distribution bar-charts. The demixing kinetics is quite clear. The gradual increase with time of both concentration amplitude and correlation distances is characteristic of a spinodal decomposition. Figure 8 shows the evolution of the mean distance between the highest chromium peaks (surpassing the mean concentration value plus two statistical standard deviations), as a function of aging time $t$ at $350^{\circ} \mathrm{C}$. The correlation distance follows a $t^{n}$ law with $n \simeq 0.2$. The value of the time exponent is very close to that predicted by the L.B.M. theory [25].

Beyond the continuous evolution of compositions towards a true bimodal distribution characterizing both $\alpha^{\prime}$ chromium rich $(\simeq 36 \%)$ and $\alpha$ chromium poor $(\simeq 9 \%)$ domains, the carefull 


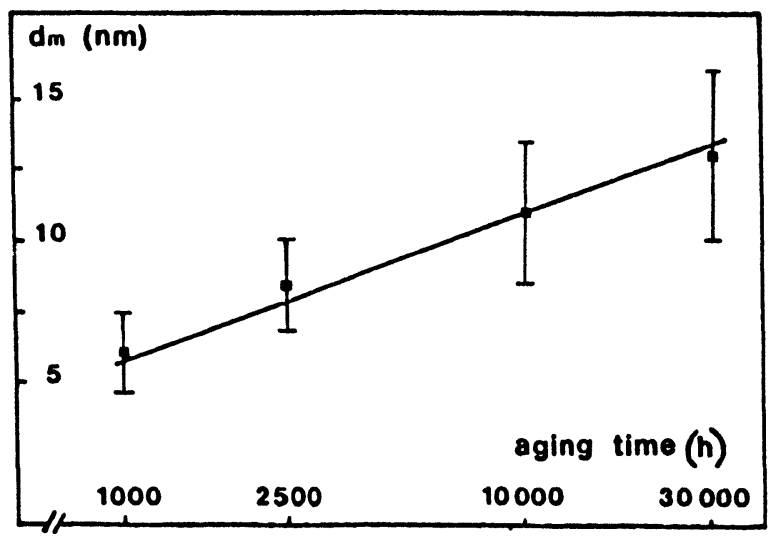

Fig. 8. - Evolution of the average wavelength of concentration fluctuations $\left(d_{\mathrm{m}}\right)$ observed in figure 7 as a function of aging time at $T=350^{\circ} \mathrm{C}$.

examination of the frequency bar-charts, reveals the occurence of $\alpha^{\prime}$ zones containing up to 62 at $\%$ of chromium. It is noticeable that after long term aging at $400^{\circ} \mathrm{C}$, the $62 \% \mathrm{Cr}$ rich domains take much more importance while the $35-40 \%$ ones tend to reduce. Such a behaviour strongly suggests a two-step evolution of the demixing kinetics. As recently reported [20], the appearance of these high Cr-peaks may be connected with the existence of long-range Cr-concentration fluctuations that occur in the aged ferrite. Local Cr-concentration modulations may give rise to various decomposition rates according to the local driving force.

\section{Long range order modulations in an incommensurate phase.}

The long Period Structures (LPS) observed in numerous ordered alloys show very intriguing phenomena. Based on $\mathrm{L1}_{2}$ cubic structures, they can be described as commensurate or incommensurate arrangements of domains bounded by conservative antiphase boundaries (APB) lying in (001) cubic planes. High resolution electron microscopy observations of $\mathrm{Cu}_{3 \pm x}$ Pd alloys show for instance that one dimensional as well as two dimensional arrays of ordered domains may occur $[26,27]$. Various topologies may also be observed according to the chemical composition or the temperature of ordering. APB's can be straight or wavy and spread over a few atomic planes $[27,28]$ and the value of the mean size of ordered domains $(M)$ may be commensurate or incommensurate with the lattice parameter $(a)$.

In this paper, we will report some atom-probe investigations on $\mathrm{Cu} 18.5 \% \mathrm{Pd}$ and $\mathrm{Cu} 20.5 \%$ Pd alloys we conducted in collaboration with the ONERA (F. Ducastelle and A. Loiseau). As HRTEM studies showed [26], [27], the (001) planes are partially disordered in $\mathrm{Cu} 20.5$ at\% $\mathrm{Pd}$ ordered at $T=485^{\circ} \mathrm{C}$. The periodicity of APB's is $M=6.24$.

In this work, FIM atom-probe techniques have been used in order to study concentration modulations which may occur in $\mathrm{Cu}_{3 \pm x}$ Pd alloys. As suggested by electron diffraction and the position of satellite spots, the composition of successive layers which are parallel to conservative APB's is modulated with the same periodicity as the antiphase modulation. Layer by layer microanalyses of one dimensional LPS in (001) oriented single crystals have been performed in order to investigate the stacking sequence of superstructure (001) plane. While high resolution electron microscopy is a well suitable technique for the observation of APB's in real space, the atom-probe is probably the most powerful tool for the investigation of concentration fluctuations on an atomic scale. 
A typical field ion image of a (001) single crystal $\mathrm{Cu} 18.5$ at\% $\mathrm{Pd}$ is given in figure 9. Antiphase boundaries are here parallel to the tip axis and lead to well visible discontinuities on the central (001) superstructure pole. Only palladium atoms are visible on this image (individual bright spots). As a result, only Pd-rich mixed planes of the $\mathrm{L1}_{2}$ ordered structure are imaged. The average value of $M\left(M=38 / a\right.$ with $a=3.7 \AA$ the lattice parameter of $\left.\mathrm{Cu}_{3} \mathrm{Pd}\right)$ is in good agreement with that determined by HRTEM $(M=10.3)$.

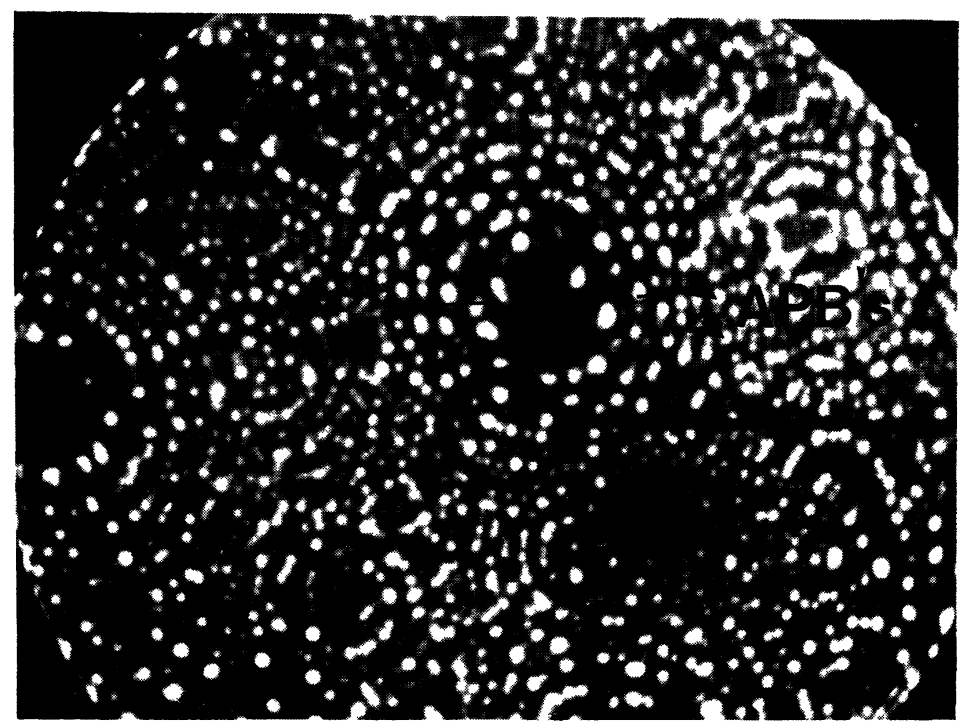

Fig. 9. - Field ion image of $\mathrm{Cu} 18.5$ at\% Pd exhibiting the presence of APB's (dashed lines). The tip radius is close to $400 \AA$ and the average magnification is around $10^{6}$. The array of parallel APB's leads to well visible discontinuities at the vicinity of the central (001) pole.



Fig. 10. - This composition profile shows the Pd concentration modulations which occur in the perpendicular direction to conservative APB's $(\perp 001)$ in $\mathrm{Cu} 20.5$ at\% Pd. 
As the three $<001>$ directions are equivalent in these single crystal materials, three types of orientation domains may be observed by FIM. Only variants for which APB's are normal to the analysis direction (or perpendicular to the tip axis, see Fig. 1) are suited for the investigation of long range order modulations. These variants are well recognizable in FIM images: conservative APB's are not visible when they are perpendicular to the tip axis (no stacking fault occur) [29].

A concentration profile related to the analysis of such a variant is provided in figure 10 . This investigation was conducted on (001) planes (// APB's) of $\mathrm{Cu} 20.5$ at\% Pd with a spatial resolution of a single atomic layer. The analysis cylinder is perpendicular to APB's. The fine scale modulations observed for palladium clearly exhibit the expected stacking sequence of superstructure (001) planes: Pd-rich layers alternate with Pd-depleted (Cu-rich) planes.

Despite the existence of statistical fluctuations from one plane to another (which are unavoidable because of the limited number of collected ions per layer $(N \simeq 36))$, one can observe the presence of a long range modulation. The composition of Pd rich layers appears to be modulated quasi-periodically. This interpretation is reinforced by the fact that the spacing between extrema is observed to oscillate between 6 and $7 d_{001}\left(a=d_{001}\right)$. As Fourier transform or autocorrelation analyses of atom-probe data show, the average wavelength of these long range order modulations $\left(\sim 6.5 d_{001}\right)$ is in good agreement with the mean width of one dimensional ordered domains as measured by HRTEM $(M=6.24)$. Further details are given in a recently published paper [29].

\section{Conclusion.}

The various investigations we have reported, demonstrate that atom-probe techniques is a powerful tool for the study of fine-scale features in materials. The instrument is capable of routinely achieving atomic resolution in both imaging and analysis of metallic alloys. The performances of atom-probe allow a number of physical processes to be studied, including phase transformations, ordering phenomena, interfaces or grain boundary segregation or even clustering effects [30]. The unlimited mass range of the TOF spectrometer as well as the possibility to detect light elements (B, Li...) give to this technique the possibility to investigate a large variety of materials. Moreover, the emergence of new generations of three dimensional atom-probes [24,31] with which the specimen can be chemically and analytically reconstructed on a nearly atomic scale, will open new fields for these techniques in material science.

\section{References}

[1] Muller E.W., Z. Phys. 131 (1951) 136-142.

[2] Muller E.W., PANITZ J.A. and McLane S.B., Rev. Sci. Instrum. 39 (1968) 83-86.

[3] KELlOG G.L. and TsONG T.T., J. Appl. Phys. 51 (1980) 1184-1193.

[4] Grovenor C.R.M., Cerezo A. and SMITH G.D.W., Microsc. Semicond. Mater. Conf. Oxford (21-23 March 1983) Inst. Phys. Conf. Ser. 67 (1983) 109-114.

[5] Chambreland S., WALDER A. and BlaVeTtE D., Acta met. 36 (1988) 3205-3215.

[6] BlavetTE D., BuCHON A. and Chambreland S., Proc. of Euromat. Aachen (nov 1989), to be published.

[7] ANDREN H.O., J. Phys. Colloq. France 47 (1986) C7. 483-488.

[8] BlaVETtE D., MENAND A., Les techniques de l'ingénieur; Analyse chimique et caractérisation (1989) p.900 1-14.

[9] Blavette D. and Menand A., Ann. Chim. 11 (1986) 321-384.

[10] MULLER M.K., Internat. Mat. Rev. 32 (1987) 221-240.

[11] BLAVETTE D. and BOSTEl A., Surf. Sci. Lett. 177 (1986) 994-398. 
[12] BLAVETTE D. and Bostel A., Acta. Met. 32 (1984) 811.

[13] KARLSSON L. and NORDEN H., J. Phys Colloq. France 45 (1984) C9 391-396.

[14] NORDEN H. and ANDREN H.O., Surf. Interface Analys. 12 (1988) 179-184.

[15] Buchon A., MENAND A. and Blavette D., Surf. Sci. (to be published)

[16] Miller M.K. and NORTON J.A., J. Phys. Colloq. France 48 (1987) C6 379-384.

[17] Sieloff D.D., BRENNER S.S. and BuRKe M.G., J. Phys. Colloq. France 47 (1986) C7 298-303.

[18] STILler K., J. Phys. Colloq. France 50 (1989) C8 329-334.

[19] AlVENSLEBen L.V., J. Phys. Colloq. France 49 (1988) C6 335-340.

[20] Auger P., Danoix F., Menand A., Bonnet S., Bourgoin J., Guttmann M., Mater. Sci. Techn. 6 (1990) 301-313.

[21] BRENNER S.S., MILlER M.K. and SOFFA W.A., Scr. Met. 16 (1982) 831-836.

[22] ZHU F., WENDT H. and HAASEN P., Scr. Met. 16 (1982) 1175-1180.

[23] Miller M.K. and BeNTley J., J. Phys. Colloq. France 47 (1986) C7 239-244.

[24] CEREZO A., GODFrey T.J., GROVENOR C.R.M., HeTHERINGTON M.G., HoYLE R.M., JAKubOVICS J.P., LIDDLE J.A., SMITH G.D.W. and WORRAL G.M., J. Microscopy 154 (1989) 215-225.

[25] LANGer J.S., BAR-ON M. and Miller H.D., Phys. Rev. $A .11$ (1975) 1417-1429.

[26] Loiseau A., VAN TENDEloO G., PORTIER R. and DuCASTElle F., J. Phys. France 46 (1985) 595-613.

[27] Brodin D., Van tendeloo G., VAN landuYt J., Amelinckx S., PORTIER R., GuYmont M. and LOISEAU A., Philos. Mag. A. 54 (1986) 395-419.

[28] Brodin D., Van tendeloo G., Van landuyt J., Amelinckx S., Loiseau A., Philos. Mag. B. 57 (1988) 31.

[29] BlavetTe D., Chambreland S., Loiseau A., Planes J., Ducastelle F., J. Phys Colloq. France 50 (1989) C8 365-370.

[30] BlavetTe D., CaRon P. and Khan T., Scr. Met. 20 (1986) 1395.

[31] Bostel A., Blavette D., Menand A. and Sarrau J.M., J. Phys. Colloq. France 50 (1989) 501-506. 